\title{
Spectral Probability Density for Broadband Seismic Ambient Noise Level
}

\author{
Endah Puspita Sari ${ }^{1}$, Melda Panjaitan ${ }^{2}$, Hery Sunandar ${ }^{2}$, Eridawati $^{1}$, Resa Idha $^{1}$ \\ ${ }^{1}$ Badan Meteorologi Klimatologi dan Geofisika, Indonesia \\ ${ }^{2}$ Universitas Budi Darma, Medan, Indonesia
}

\begin{tabular}{l}
\hline \hline Article Info \\
\hline Article history: \\
Received March 1, 2021 \\
Revised March 10, 2021 \\
Accepted March 23, 2021 \\
\hline
\end{tabular}

\section{Keywords:}

Spectral,

Ambient Noise,

PDFPSD,

Seismic,

Broadband.

\begin{abstract}
A B S T R A C T
The time-series approach is commonly utilized to get to the estimation of the likelihood thickness work of control ghostly densities (PDF PSD) of waveform information. This paper is concerned with the introduction of the evaluation of waveform commotion to degree the likelihood thickness work (PDF) be done inside, we utilized the metadata from a stock, a parser occurrence of DNP (Denpasar, Bali, Indonesia), IGBI (Ingas, Bali, Indonesia), and PLAI (Plampang, NTB, Indonesia) from BMKG IA-Networks and computations are based on the schedule utilized by McNamara Demonstrate. The point of this paper to characterize the current and past execution of the stations and recognizing the data on clamor levels at BMKG IA-Networks Station. The result of this paper shows the consistency of the unearthly is displayed the DNP, IGBI, and PLAI organize to confirm the quality of information conjointly acts as a test execution broadband arrange to the time taken by the broadband organize within the field and examination the Lombok earthquake in 2018 .
\end{abstract}

This is an open access article under the CC BY-SA license.

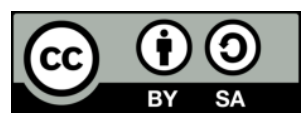

\section{Corresponding Author:}

Endah Puspita Sari,

Badan Meteorologi Klimatologi dan Geofisika, Indonesia,

Jl. Ngumban Surbakti No.15, Sempakata, Kec. Medan Selayang, Kota Medan, Sumatera Utara 20131.

Email: endahbmkg2012@gmail.com

\section{INTRODUCTION}

Ambient noise level or background noise level is the contextual sound level sound pressure level at a given location in situ. The furthermost common source of ambient noise is from the exploit of human beings at or near the surface of the Earth. In the previous noise studies of the earthquake, there is no attempt to screen the continuous waveforms to eliminate body and surface waves from naturally occurring processing earthquake signals. In this case, they are low-probability occurrences even at low power levels (small magnitude events) related to the ambient surroundings at the seismic station.

The observed probability of the power spectral density as a tool to assess the field performance of earthquake monitoring system and the statistical distribution of noise levels across the frequency spectrum [1]. The more statistically approach requires large sample sizes, which become the norm as advances in probability power spectral density [2], [3]. In this study, we use the datasets of the broadband network from DNP, IGBI, and PLAI which deployed in BMKG network, Indonesia. Datasets on seismic background noise are collected, amongst others, for assessing the suitability of sites for permanent seismic recordings. One of the most important steps to be undertaken before the selection of suitable seismological recording sites is the investigation of seismic background noise.

The power spectral density spectrum estimation, periodogram is not a consistent estimate of the power spectrum [4], [5]. So, non-parametric methods are used for power spectrum estimation by 
smoothing and averaging operations which are directly implied on the periodogram or the autocorrelation [6], [7]. The aim of this paper to characterize the current and past performance and detecting the information on noise levels at BMKG IA-Networks Station.

\section{DATA AND METHOD}

The time series of waveform data were recorded in three locations in Indonesia: DenpasarBali, Ingas - Bali, and Plampang - Nusa Tenggara Barat (NTB) for one month in August 2018. The waveform data were employed from Indonesia Tsunami Early Warning System (Ina-TEWS) BMKG-IA network in Table 1.

Table 1. Seismic Station of BMKG-IA Network and Location

\begin{tabular}{lllll}
\hline No & Station & Latitude & Longitude & Networks \\
\hline 1. & PLAI-IA & -8.83 & 117.78 & Indonesia \\
2. & IGBI -IA & -8.62 & 115.15 & Indonesia \\
3. & DNP -IA & -8.68 & 115.21 & Indonesia \\
\hline
\end{tabular}

In Table 1, shown the seismic station which recorded the SEED channel, the network code is IA (Indonesia), with channel code is BHZ (component Z).

The time series data in mini-SEED format obtained from the three stations were used for this study. An average of an hour-long vertical, Z component data for one month on August 2018 from each station and their respective noise spectra were plotted using spectral analysis methods. We use the power spectra to amplitude measurements [8]-[10]. The spectral analysis is commonly used to make the correction of attenuation and instrument displacement spectrum and determine the flat spectral level and corner frequency from which the seismic [6], [11]-[13].

The flow diagram of Probability Density Function and Power Spectral Density can show in Fig.1. The waveform data indicated the pre-processing by read of waveform data in hour.

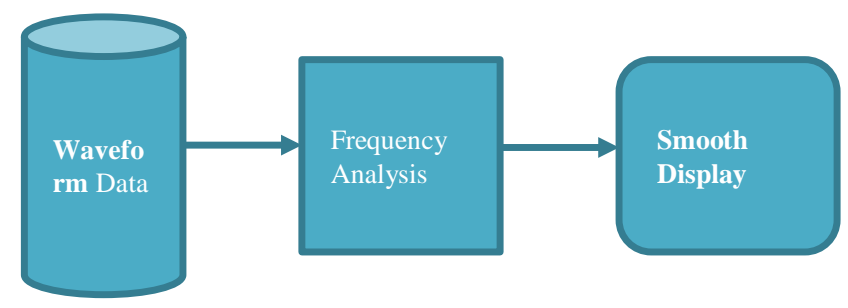

Figure 1. PDF/PSD flow

In this case, we remove instrument response and split into segment. The frequency analysis using FFT each segment and not only compute power for each segment but also compute average power for the hour interval. The smooth display shown the store of PSD and smoothing of power in octave.

\section{RESULTS AND DISCUSSION}

The figure [2-4] shows the result of probability power spectral density, which related plotted in power amplitude (dB) versus periods (s) [7], [12], [14]-[17]. The upper black solid line means that the New High Noise Model (NHNM) and the lower means that the New Low Noise Model. The DNP in figure 1 and PLAI in figure 3 networks are represented the spectral probability density closer to the upper line or the network means the new high noise model. In this case, the DNP and PLAI have a characterization of outliers and their influence on the noise level. The PSD distribution in Fig. 2 shows the noise at the DNP, the minimum and mode power closely follow the especially in the frequency range above $1 \mathrm{~s}$. 


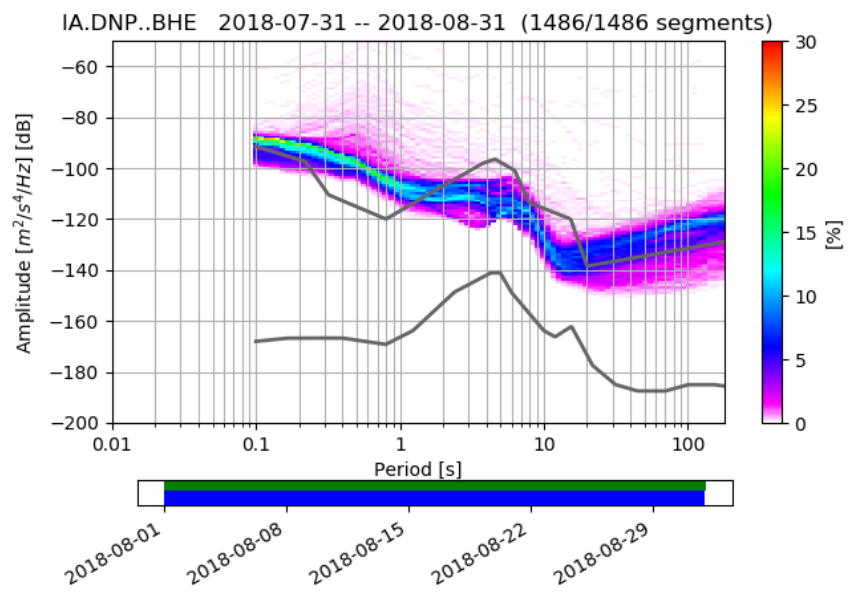

Figure 2. The PSD and PDF for DNP Broadband Seismic Network. The function is calculated using data from 1 to 30 August 2018

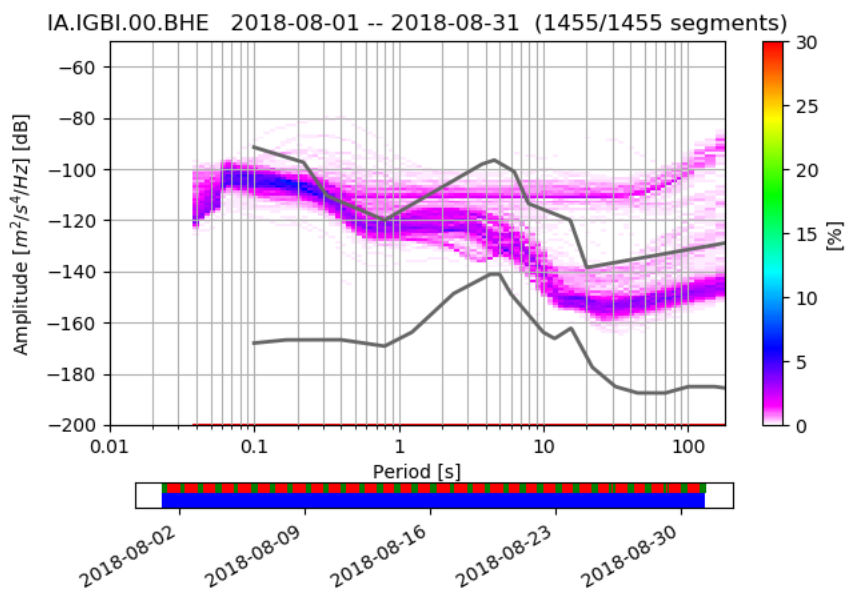

Figure 3. The PSD and PDF for IGBI Broadband Seismic Network. The function is calculated using data from 1 to 30 August 2018

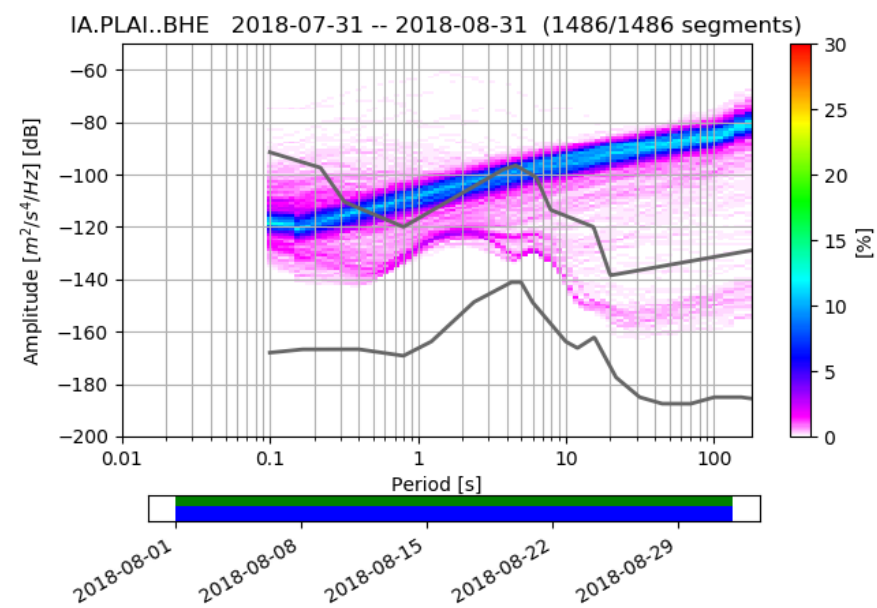

Figure 4. The PSD and PDF for PLAI Broadband Seismic Network. The function is calculated using data from 1 to 30 August 2018

In this case, the spectrum probability density of IGBI network is too flat, it means that there are several of the waveforms in August is missed, it's related to the gap of the waveform. The gaps can be represented in the period in Fig. 4. The other case, the spectral probability density is represented between the NHNM and NLNM. The green patches in periods represent available data, 
and red patches represent gaps in the stream that were added to the probability power spectral density [9][18][10].

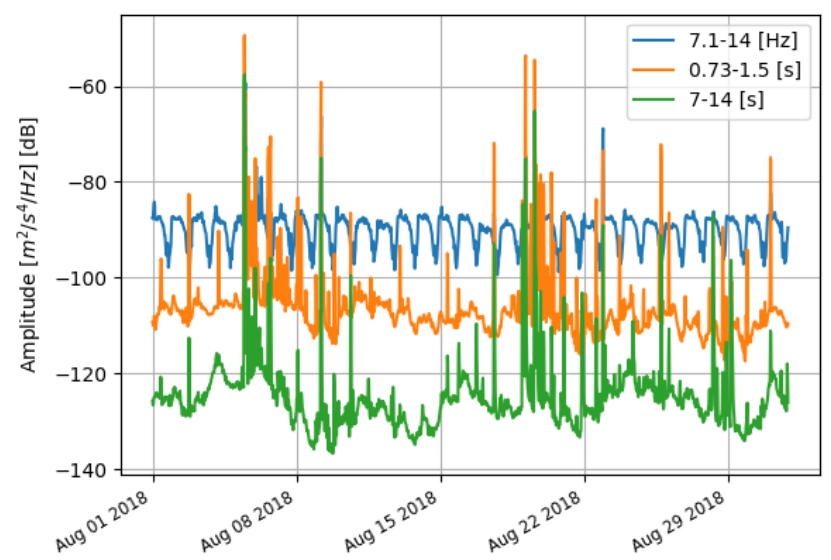

Figure 5. The Spectral Probability Density value of DNP

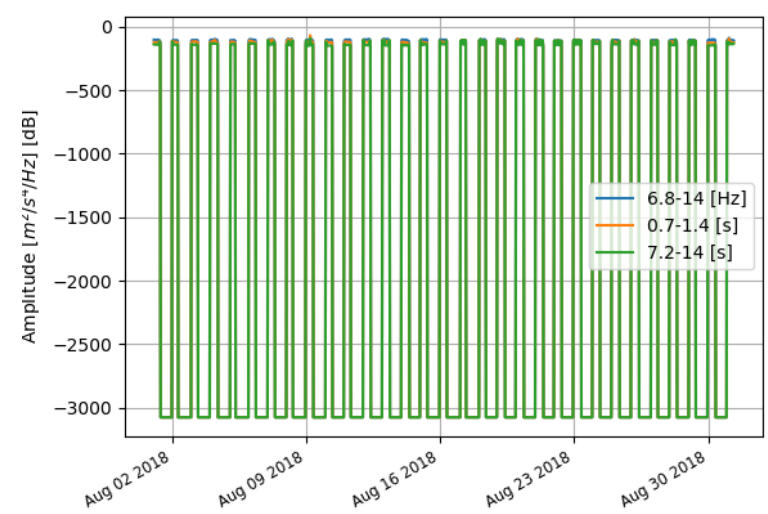

Figure 6. The spectral probability density value of IGBI

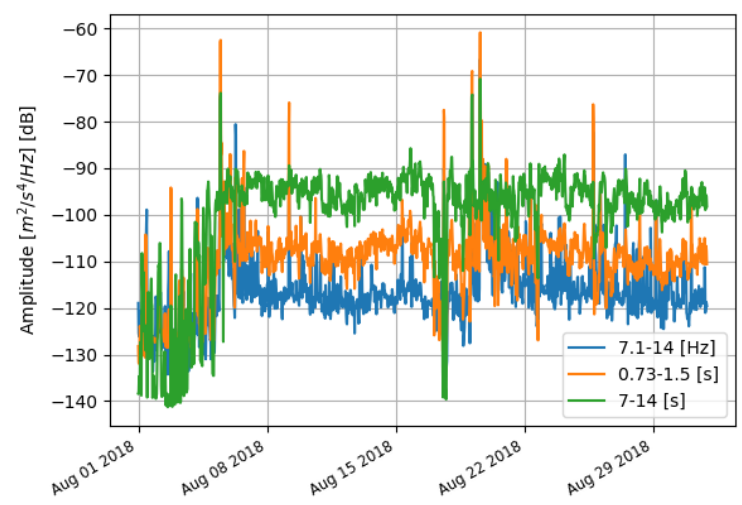

Figure 7. The Spectral probability density value of PLAI

In figure [5-7] show the information on metadata will be correctly picked for the respective start time of the data-trace. This means that DPN, IGBI and PLAI instrument changes are correctly taken into account during response removal. The time series of power spectral density of DPN, IGBI and PLAI network values can also be extracted from the probability power spectral density by accessing the property PSD values and plotted using the plot temporal method[19], [20]. 


\section{CONCLUSION}

The data used in the calculations are not separated out of earthquake, system and instrumental failures. The PSDPDF is determined power spectral of background noise level. We have presented the consistency of the spectral probability density is presented the DNP, IGBI, and PLAI network to verify the quality of data and also acts as a test performance broadband network to the time taken by the broadband network in the field and analysis the Lombok earthquake in 2018.

\section{REFERENCES}

[1] N. D. Merchant, T. R. Barton, P. M. Thompson, E. Pirotta, D. T. Dakin, and J. Dorocicz, "Spectral probability density as a tool for ambient noise analysis," J. Acoust. Soc. Am., vol. 133, no. 4, pp. EL262EL267, 2013, doi: 10.1121/1.4794934.

[2] K. Tarigan, M. Sinambela, A. T. Simanullang, H. Sunandar, and S. B. Sinaga, "The Characteristics Influence of the Seismic Signal Noise Using Spectral Analysis," J. Phys. Conf. Ser., vol. 1116, no. 3, 2018, doi: 10.1088/1742-6596/1116/3/032041.

[3] E. Darnila, M. Ula, K. Tarigan, T. Limbong, and M. Sinambela, "Waveform analysis of broadband seismic station using machine learning Python based on Morlet wavelet," IOP Conf. Ser. Mater. Sci. Eng., vol. 420, p. 012048, 2018, doi: 10.1088/1757-899X/420/1/012048.

[4] Y. Vaezi et al., "Seismic signals and noise," Geophys. J. Int., vol. 2, no. 1, pp. 33-47, 2004, doi: 10.2312/GFZ.NMSOP-2.

[5] M. P. Mounika, K. Himaja, K. S. Ramesh, S. K. Rao, and T. V. Chandra, "Power spectrum analysis of seismic data for an earthquake using bartlett algorithm," Int. J. Pure Appl. Math., vol. 114, no. 10 Special Issue, pp. 221-229, 2017.

[6] Á. Katalin, "Studying noise measurement and analysis," Procedia Manuf., vol. 22, pp. 533-538, 2018, doi: 10.1016/j.promfg.2018.03.078.

[7] H. R. Gupta, R. Mehra, and S. Batan, "Power Spectrum Estimation using Welch Method for various Window Techniques," Int. J. Sci. Res. Eng. Technol., vol. 2, no. 6, pp. 389-392, 2013, [Online]. Available: www.ijsret.org.

[8] P. Bormann, "Seismic signals and noise," Bormann, P.(ur.), vol. 1, no. August, pp. 1-34, 2002, doi: 10.2312/GFZ.NMSOP-2.

[9] D. E. Mcnamara et al., "A Real-time Seismic Noise Analysis System for Monitoring Data Quality and Station Performance,” p. 2006, 2006.

[10] D. E. McNamara and R. P. Buland, "Ambient noise levels in the continental United States," Bull. Seismol. Soc. Am., vol. 94, no. 4, pp. 1517-1527, 2004, doi: Doi 10.1785/012003001.

[11] M. M. Haney, J. Power, M. West, and P. Michaels, "Causal Instrument Corrections for Short-Period and Broadband Seismometers,” Seismol. Res. Lett., vol. 83, no. 5, pp. 834-845, 2012, doi: $10.1785 / 0220120031$.

[12] A. el-aziz K. Abd el-aal and M. S. Soliman, "New Seismic Noise Models Obtained Using Very Broadband Stations," Pure Appl. Geophys., vol. 170, no. 11, pp. 1849-1857, 2013, doi: 10.1007/s00024-013-06407.

[13] R. Andrés and P. Guridy, "Seismic Background Noise of Puerto Rico By," 2008.

[14] M. Ula, E. Darnila, P. Siagian, L. Siagian, Peristiwanto, and M. Sinambela, "Machine learning on waveform spectral analysis of nuclear explosion from broadband seismic station in Indonesia," IOP Conf. Ser. Mater. Sci. Eng., vol. 420, p. 012047, 2018, doi: 10.1088/1757-899X/420/1/012047.

[15] A. M. Reddy, B. Jayasree, S. K. Rao, and V. L. Bharathi, "Analysis of Power Spectrum Density on Earthquake Data Using Modified Covariance Algorithm,” vol. 114, no. 10, pp. 183-190, 2017.

[16] J. Berger, P. Davis, and G. Ekström, "Ambient Earth noise: A survey of the Global Seismographic Network,” J. Geophys. Res. Solid Earth, vol. 109, no. 11, pp. 1-10, 2004, doi: 10.1029/2004JB003408.

[17] K. U. Afegbua and F. O. Ezomo, "Evaluation of performance of z-component of Nigerian seismographic stations from spectral analysis," vol. 8, no. 11, pp. 428-442, 2013, doi: 10.5897/IJPS2013.3833.

[18] D. E. McNamara, C. R. Hutt, L. S. Gee, H. M. Benz, and R. P. Buland, "A Method to Establish Seismic Noise Baselines for Automated Station Assessment," Seismol. Res. Lett., vol. 80, no. 4, pp. 628-637, 2009, doi: 10.1785/gssrl.80.4.628.

[19] D. Rodríguez-Navarro, J. L. Lázaro-Galilea, I. Bravo-Muñoz, A. Gardel-Vicente, F. Domingo-Perez, and G. Tsirigotis, "Mathematical model and calibration procedure of a PSD sensor used in local positioning systems," Sensors (Switzerland), vol. 16, no. 9, pp. 1-26, 2016, doi: 10.3390/s16091484.

[20] P. Hall and U. S. River, Spectral Analysis of Signals. 2009. 